\title{
Energy cost and body centre of mass' 3D intracycle velocity variation in swimming
}

\author{
Pedro Figueiredo • Tiago M. Barbosa • \\ João Paulo Vilas-Boas · Ricardo J. Fernandes
}

Received: 28 April $2011 /$ Accepted: 9 December 2011

(C) Springer-Verlag 2012

\begin{abstract}
The purpose of this study was to examine the relationship between the energy cost $(C)$ and the 3D intracycle velocity variation (IVV; swimming direction- $x$, vertical $-y$ and lateral $-z$ axes) throughout the $200 \mathrm{~m}$ front crawl event. Ten international level swimmers performed a maximal $200 \mathrm{~m}$ front crawl swim followed by 50, 100 and $150 \mathrm{~m}$ bouts at the same pace as in the $200 \mathrm{~m}$ splits. Oxygen consumption was measured during the bouts and blood samples were collected before and after each one. The $C$ was calculated for each $50 \mathrm{~m}$ lap as the ratio of the total energy expenditure (three energy pathways) to the distance. A respiratory snorkel and valve system with low hydrodynamic resistance was used to measure pulmonary ventilation and to collect breathing air samples. Two above water and four underwater cameras videotaped the swim bouts and thereafter APAS was used to assess the centre of mass IVV ( $x, y$ and $z$ components). The increase in the $C$ was significantly associated with the increase in the IVV
\end{abstract}

Communicated by Klaas R Westerterp.

P. Figueiredo $(\bowtie)$. J. P. Vilas-Boas · R. J. Fernandes

Centre of Research, Education, Innovation and Intervention in Sport, Faculty of Sport, University of Porto,

Rua Dr. Plácido Costa, 91, 4200-450 Porto, Portugal

e-mail: spafg@vodafone.pt

P. Figueiredo · J. P. Vilas-Boas · R. J. Fernandes Porto Biomechanics Laboratory, University of Porto,

Rua Dr. Plácido Costa, 91, 4200-450 Porto, Portugal

T. M. Barbosa

Research Centre in Sport, Health and Human Development,

Vila Real, Portugal

T. M. Barbosa

Polytechnic Institute of Bragança, Campus de Santa Apolónia, Apartado 1038, 5301-854 Bragança, Portugal in $x$ for the first $50 \mathrm{~m}$ lap $(R=-0.83, P<0.01)$. It is concluded that the IVV relationship with $C$ in a competitive event does not present the direct relationship found in the literature, revealing a great specificity, which suggests that the relation between these two parameters could not be used as a performance predictor in competitive events.

Keywords Biophysics - Energetics - Front crawl · Kinematics

\section{Introduction}

Swimming is characterized by the intermittent application of propulsive forces to overcome a velocity-dependent water resistance (i.e. hydrodynamic drag force). Swimming propulsion is produced by a combination of trunk, arm and leg movements resulting in non-uniform body movement, evidencing intracycle velocity variation (IVV; Barbosa et al. 2010b; Vilas-Boas et al. 2010). As the four conventional techniques use different combinations of trunk, arm and leg actions, the IVV is quite different among them (Craig and Pendergast 1979). The swimming velocity $(v)$ is the product of the stroke frequency (SF) by the distance the body moves through the water within each stroke cycle (SL). The generation of a given $v$ requires a certain metabolic power output $\left(\dot{E}_{\text {tot }}\right)$ that is also velocity dependent (di Prampero 1986). Front crawl has been considered the most efficient swimming technique due to the higher continuity of the arms propulsive actions (Barbosa et al. 2010b; Vilas-Boas et al. 2010). Moreover, when compared to the other swimming techniques, the IVV in front crawl has been considered as very low or even negligible (Alves et al. 1996; Craig and Pendergast 1979; Holmer 1983; Kjendlie et al. 2004), whereby its energetic profile was 
considered the lowest from all swim techniques (Barbosa et al. 2006a; Holmer 1974). Meanwhile, several authors pointed out that an increased IVV leads to a higher amount of mechanical work, lowering swimming efficiency, as compared to uniform movement; an increase of $10 \%$ of $v$ within a stroke cycle results in an additional work demand of about 3\% (Nigg 1983), which seems to be due to the necessity of overcoming the hydrodynamic drag force (Toussaint and Beek 1992). In this sense, the magnitude of the IVV is considered as a valid estimator of swimming efficiency (Vilas-Boas et al. 2010).

The number of studies regarding the relationship between the energetics and the biomechanical domains in competitive swimming is increasing (Vilas-Boas 2010). Alves et al. (1996) observed a significant relationship between the hip's horizontal IVV (IVV $x$ ) and the energy cost $(C)$ of backstroke swimming at submaximal velocities. The same authors did not report any relationship between the $C$ and the IVVx in front crawl, as well as (Kjendlie et al. 2004) during $4 \times 25 \mathrm{~m}$ front crawl at submaximal velocities. For the breaststroke, Vilas-Boas (1996) found a non-significant correlation between the $C$ and the hip's IVV $x$, but when performing individual correlations both variables were highly related. Concerning the butterfly, Barbosa et al. (2005) concluded that high IVV was well related with lower swimming efficiency (inducing an increase in the $C$ ). In addition, Barbosa et al. (2006b) found that the $C$ increases were strongly related to the IVV $x$ for all swim techniques, when partial correlations controlling the effect of $v$ were computed.

The above reported studies assessed the relationship between the IVV and the $C$ throughout progressive and intermittent protocols using a large swim velocity range (Alves et al. 1996; Barbosa et al. 2005; Vilas-Boas 1996). Moreover, the IVV was evaluated for an anatomical landmark (i.e. hip) (Alves et al. 1996; Vilas-Boas 1996) or the body centre of mass (Barbosa et al. 2005, 2006b). Nevertheless, both studies only assessed the IVV in the swimming direction, and the lateral and vertical directions were not considered.

Complementarily, several works were published regarding the stroke mechanics variations (Craig et al. 1985; Seifert and Chollet 2009; Barbosa et al. 2010a), segmental or body kinematics (Figueiredo et al. 2009; Psycharakis et al. 2010) and energetic variables (Ribeiro et al. 2010; Fernandes et al. 2006; Reis et al. 2010). However, to our knowledge, no attempt was made to assess the relationships between the $C$ and the IVV throughout a swimming event.

The purpose of this study was to examine the relationships between the centre of mass' IVV in the three axes of motion (swimming direction $-x$, vertical $-y$ and lateral $-z$ ) and the $C$ of locomotion throughout the 200-m freestyle event.

\section{Materials and methods}

\section{Subjects}

Ten highly trained competitive male swimmers volunteered to participate in this study (mean $\pm 1 \mathrm{SD}$ : aged $21.6 \pm 2.4$ years; height $185.2 \pm 6.8 \mathrm{~cm} ;$ arm span $188.7 \pm 8.4 \mathrm{~cm}$; body mass $76.4 \pm 6.1 \mathrm{~kg}$; percentage of adipose tissue $10.1 \pm 1.8 \%$ ). All subjects (mean performance over a $200 \mathrm{~m}$ freestyle event $=91.6 \pm 2.1 \%$ of the $25 \mathrm{~m}$ pool world record) had $11.0 \pm 3.5$ years experience as competitive swimmers. All subjects gave their written informed consent before participation. The study was approved by the local ethics committee and was performed according to the Declaration of Helsinki.

\section{Experimental design}

On the testing day, each swimmer performed an individual warm-up, consisting of low to moderate intensity $1,000 \mathrm{~m}$ aerobic swimming. Thereafter, swimmers performed a $200 \mathrm{~m}$ maximal front crawl bout. All tests were conducted in a $25 \mathrm{~m}$ indoor swimming pool, using a push start and open turns without gliding. After $90 \mathrm{~min}$ of active rest interval, swimmers performed a $50 \mathrm{~m}$ front crawl bout at the same speed obtained in the $200 \mathrm{~m}$ bout. Twentyfour hours later, swimmers performed 150 and $100 \mathrm{~m}$ bouts, with a $90 \mathrm{~min}$ active recovery. Swim pacing for the 50,100 and $150 \mathrm{~m}$ bouts was controlled by a visual light pacer placed in the bottom of the pool (TAR 1.1, GBKElectronics, Aveiro, Portugal). At the end of each test blood lactate accumulation was measured. To simulate as much as possible the $200 \mathrm{~m}$ test conditions, swimmers used the respiratory snorkel and valve system also in the 50, 100 and $150 \mathrm{~m}$ swims.

\section{Data collection and analysis}

The $200 \mathrm{~m}$ bout was recorded with six stationary and synchronized video cameras (Sony, DCR-HC42E, Tokyo, Japan): four below (optical axes ranged from 75 to $110^{\circ}$ ) and two above the water surface (optical axes was $\sim 100^{\circ}$ ). The recorded space was calibrated with a volume $(3 \times 2 \times 3 \mathrm{~m}$ for the horizontal, vertical and lateral directions) and 30 calibration points. Synchronization of the images was attained using a pair of lights observable in the field of view of each camera. One stroke cycle for each $50 \mathrm{~m}$ lap was analysed. Twenty-one anatomical landmarks were used: the vertex of the head, seventh cervical vertebra, mandible (mental protuberance), and the right and left tip of the third distal phalanx of the finger, wrist axis, elbow axis, shoulder axis, hip axis, knee axis, ankle axis, fifth metatarsophalangeal joint and the tip of the first 
phalanx. Three-dimensional reconstruction of the 21 body landmarks, digitised manually and frame $(50 \mathrm{~Hz})$ by frame, was obtained using APAS (Ariel Performance Analysis System, Ariel Dynamics, Inc., USA) and computed using DLT (Abdel-Aziz and Karara 1971). Zatsiorsky anatomical model adapted by de Leva (1996), widely used in the literature (e.g. Barbosa et al. 2005; Figueiredo et al. 2011b), was utilized. After residual analysis for a wide range of cut-off frequencies, $6 \mathrm{~Hz}$ was selected as the optimal cutoff frequency for the smoothing of the data using a low pass digital filter incorporated in the software. Root mean square reconstruction errors of 12 validation points on the calibration frame, which did not serve as control points, were, respectively for $x, y$ and $z$ axes: (1) 3.9, 3.7 and $3.3 \mathrm{~mm}$ for above the water view and (2) 3.4, 2.5 and $3.2 \mathrm{~mm}$ for the underwater view (for more detailed analysis cf. Figueiredo et al. 2011a). These results showed good accuracy as previously observed (Gourgoulis et al. 2008). To determine the reliability of the digitizing process, a swimmer was digitized ten times for all the six video cameras through the stroke cycle. Small standard deviation for the repeated digitisations indicated acceptable reliability for velocity being $0.03,0.02$ and $0.03 \mathrm{~m} \mathrm{~s}^{-1}$ for $v x, v y$ and $v z$, respectively, similar to the ones reported by Psycharakis and Sanders (2009).

CM' velocity $\left(v_{\mathrm{cm}}\right)$ was calculated by dividing the horizontal displacement of the CM in one stroke cycle by the total duration of the stroke cycle. The SL was the $x$ displacement of the CM during the stroke cycle. The SF was determined from the time needed to complete a stroke cycle. The centre of mass' IVV in the three axes was computed as the coefficient of variation (SD/mean) as suggested before (Barbosa et al. 2005; Figueiredo et al. 2009; Vilas-Boas et al. 2010). The use of the coefficient of variation seems to be the only sensitive approach to the mean swimming velocity and to the dispersion of the instantaneous velocity throughout the stroke cycle, and not to a single or couple of instantaneous moments; therefore, mathematically, it is the more accurate method for the quantification of IVV (Vilas-Boas et al. 2010). In addition, the coefficient of variation has been suggested as a reliable statistic to distinguish the economy of swimming (Alves et al. 1996; Barbosa et al. 2005; Nigg 1983; Vilas-Boas 1996).

Oxygen uptake $\left(\mathrm{VO}_{2}\right)$ was recorded by the telemetric gas exchange system (K4b ${ }^{2}$, Cosmed, Rome, Italy) continuously during the $200 \mathrm{~m}$ front crawl test. This equipment was connected to the swimmer by a low hydrodynamic resistance respiratory snorkel and valve system previously validated (Keskinen et al. 2003). Expired gas concentrations were measured breath by breath and averaged every $5 \mathrm{~s}$. Net $V \mathrm{O}_{2}$ was calculated subtracting the resting $V \mathrm{O}_{2}$ from the measured $V \mathrm{O}_{2}$.
Before and after each test capillary blood samples $(5 \mu \mathrm{l})$ were collected from the earlobe to assess rest and postexercise (at 1, 3, 5, and $7 \mathrm{~min}$ ) blood lactate ([La $\left.]_{b}\right)$ using a portable lactate analyser (Lactate Pro, Arkray, Inc., Japan) that has been shown to be accurate (Baldari et al. 2009). The $v$ for each lap was calculated by the ratio between distance and time using a stopwatch.

$C$ was obtained through the ratio between the $\dot{E}_{\text {tot }}$ and the mean $v, \dot{E}_{\text {tot }}$ was considered as the sum of the three energy sources (aerobic, alactic and lactic) as previously proposed (Capelli et al. 1998; Figueiredo et al. 2011b; Zamparo et al. 2011). The aerobic contribution (Aer) in each of the four $50 \mathrm{~m}$ laps was calculated from the time integral of the net $V \mathrm{O}_{2}$ versus time relationship (equivalent

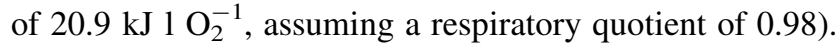
The anaerobic contribution was obtained by the sum of the energy derived from glycolysis (Anl) plus that derived from phosphocreatine (PCr) splitting in the contracting muscles (AnAl). Lactic contribution was considered as:

$\mathrm{Anl}=b[\mathrm{La}]_{b \text { net }} M$

where $[\mathrm{La}]_{b \text { net }}$ is the net accumulation of lactate after exercise, $b$ is the energy equivalent for lactate accumulation in blood $\left(2.7 \mathrm{ml} \mathrm{O}_{2} \mathrm{mM}^{-1} \mathrm{~kg}^{-1}\right.$ as used before, di Prampero et al. 1978) and $M$ is the mass of the subject. Afterwards, Anl was then expressed in kJ assuming an

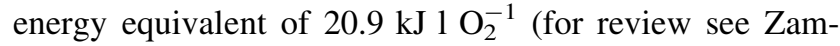
paro et al. 2011).

Alactic contribution was considered as:

$\mathrm{AnAl}=\operatorname{PCr}\left(1-\mathrm{e}^{-t / \tau}\right) M$

where $t$ is the time duration, $\tau$ is the time constant of $\mathrm{PCr}$ splitting at work onset (considered to be $23.4 \mathrm{~s}$, as proposed by Binzoni et al. 1992), $M$ is the mass of the subject and $\mathrm{PCr}$ is the phosphocreatine concentration at rest. The latter was assumed to be equal to $27.75 \mathrm{mM} \mathrm{kg}^{-1}$ muscle (wet weight) in a maximally active muscle mass (Figueiredo et al. 2011b; Prampero et al. 2003). AnAl was expressed in $\mathrm{kJ}$ by assuming a $\mathrm{P} / \mathrm{O}_{2}$ ratio of 6.25 and an energy equivalent of $0.468 \mathrm{~kJ} \mathrm{mM}^{-1}$ for swimming maximal velocities (Capelli et al. 1998; Zamparo et al. 2011). The AnAl contribution for each lap was then calculated as the difference in the AnAl before and after each lap.

Statistical analysis

Mean $( \pm 1 \mathrm{SD})$ computations for descriptive analysis were obtained for all variables selected (data normal distribution verified with Shapiro-Wilk's test). A one-way repeated measures ANOVA was used to compare the kinematical variables along the $200 \mathrm{~m}$ event. When a significant $F$ value was achieved, Bonferroni post hoc procedure was 
performed to locate the pairwise differences. Linear regressions between the energetic $(C)$ and the biomechanical (IVV in $x, y$ and $z$ axes) variables were computed, as well as their coefficients of determination for each lap. Partial correlations between the IVV ( $x, y$ and $z)$ and the $C$, controlling the effect of $v$, for each lap were also computed. To further analyse the relationship between the energetic and the biomechanical variables over the $200 \mathrm{~m}$, involves a repeated measurements design, a within subjects correlation coefficient was reported, which accounts for the lack of independence among the repeated measurements by removing the variation between subjects, as proposed by Bland and Altman (1995a).

Also, a between subjects correlation coefficient for repeated measurements design (Bland and Altman 1995b) was reported for the mean values of the $200 \mathrm{~m}$, examining whether subjects with a high value on the IVV $(x, y$ and $z$ ) also tend to have a high value on the $C$. All statistical analysis was performed using STATA 10.1 (StataCorp, USA) and the level of statistical significance was set at
$P \leq 0.05$. Since a limited sampled is used, effect size was computed with Cohen's $f$. It was considered a (Cohen 1988): (1) small effect size if $0 \leq|f| \leq 0.10$; (2) medium effect size if $0.10<|f| \leq 0.25$ and; (3) large effect size if $|f|>0.25$.

\section{Results}

Figure 1 shows the mean $( \pm 1 \mathrm{SD})$ values of the biomechanical parameters assessed in each $50 \mathrm{~m}$ lap of the $200 \mathrm{~m}$ front crawl event. The $v$ decreased significantly from the first lap to the remain ones $\left(F_{(3,27)}=24.58\right.$, $P<0.001, f=1.26$ ). The SL remained constant for the first three laps, whereas a decrease was observed in the fourth lap $\left(F_{(3,27)}=4.56, P=0.01, f=0.32\right)$. SF only presented differences from lap 1 to lap $3\left(F_{(3,27)}=5.08\right.$, $P=0.01, f=0.39$ ).

Figure 2 presents the relationship between the $C$ and the $\operatorname{IVV}(x, y$ and $z)$ for each $50 \mathrm{~m}$ lap. The relationship
Fig. 1 Mean $( \pm 1 \mathrm{SD})$ values of velocity $(v)$, stroke length (SL) and stroke frequency $(\mathrm{SF})$ for the $200 \mathrm{~m}$ front crawl event. ${ }^{\mathrm{a}}$ Significantly different from the first lap. $P<0.05$
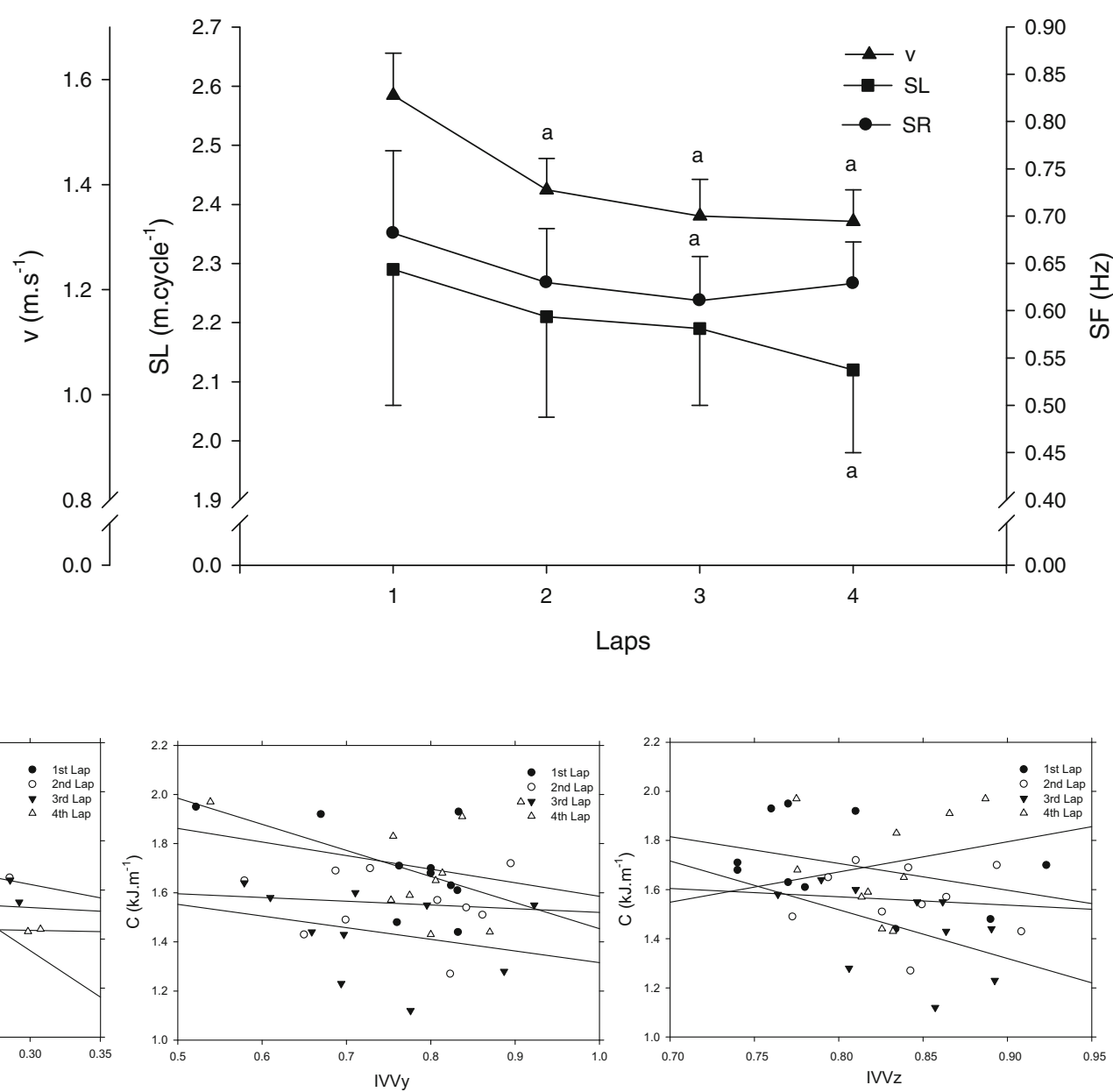

Fig. 2 Energy cost $(C)$ as a function of intracycle velocity variation (IVV) in horizontal (left panel), vertical (centre panel) and lateral (right panel) axes in the four laps of the $200 \mathrm{~m}$ front crawl event. Lines represent linear regression analysis $(N=10), P<0.05$ 
Table 1 Partial correlation values $(N=10)$, controlling the swimming velocity effect, between intracycle velocity variation (IVV) in swimming direction $(x)$, vertical $(y)$ and lateral $(z)$ axes and the energy cost $(C)$ for each $50 \mathrm{~m}$ lap of the $200 \mathrm{~m}$ front crawl event

\begin{tabular}{lllr}
\hline & IVV $x$ versus $C$ & IVV $y$ versus $C$ & IVV $z$ versus $C$ \\
\hline First lap & $R=-0.65(P=0.05)$ & $R=-0.07(P=0.85)$ & $R=-0.46(P=0.21)$ \\
Second lap & $R=-0.10(P=0.79)$ & $R=-0.11(P=0.78)$ & $R=-0.11(P=0.78)$ \\
Third lap & $R=-0.01(P=0.98)$ & $R=-0.33(P=0.39)$ & $R=-0.49(P=0.18)$ \\
Fourth lap & $R=-0.19(P=0.62)$ & $R=-0.05(P=0.91)$ & $R=0.50(P=0.17)$ \\
\hline
\end{tabular}

between $C$ and IVV $x$ in the first $50 \mathrm{~m}$ lap was statistically significant $(R=-0.83, \quad P=0.003)$ evidencing that decreases in the IVV $x$ promoted an increase in the $C$. The relationships computed for the other axes of motion $(y$ and $z$ axes) and for the second, third and fourth $50 \mathrm{~m}$ laps showed to be non-significant.

As $v$ is a co-variable of the $C$ and the IVV, partial correlation values between the IVV $(x, y$ and $z)$ and the $C$ for each $50 \mathrm{~m}$ lap of the $200 \mathrm{~m}$ front crawl event were computed (Table 1). Thus when controlling the $v$ effect, the same trend was observed as the linear regressions: only the relationship between the $C$ and the IVV $x$ in the first $50 \mathrm{~m}$ lap was significant $(R=-0.65, P=0.05)$. So, during this competitive event, increases in the IVV $x$ were explained by increases in the $C$, although only in the first lap.

To further study the relationship of the energetics and the biomechanical variables throughout the $200 \mathrm{~m}$ event, within and between subjects, correlation coefficients were computed (Table 2). Data showed an inverse relationship between the $C$ and the IVV $(x, z)$ during the $200 \mathrm{~m}$ within the same swimmer.

\section{Discussion}

The purpose of this study was to examine the relationship between the body centre of mass' IVV in the $x, y$ and $z$ axes with the $C$ during a $200 \mathrm{~m}$ front crawl event. The IVV $x$ was inversely associated with the $C$ only for the first lap when analysing each $50 \mathrm{~m}$ length. The IVV $x$ and the IVV $z$ were also inversely related with the $C$, when considering the

Table 2 Within $(N=40)$ and between $(N=10)$ subjects correlation coefficient values between intracycle velocity variation (IVV) in swimming direction $(x)$, vertical $(y)$ and lateral $(z)$ axes and the energy cost $(C)$ for the $200 \mathrm{~m}$ front crawl event (taking in consideration the four studied laps)

\begin{tabular}{lll}
\hline Axis & Within subjects & $\begin{array}{l}\text { Between subjects } \\
C \text { versus IVV }\end{array}$ \\
\hline$x$ & $R=-0.34(P=0.03)$ & $R=-0.33(P=0.39)$ \\
$y$ & $R=0.07(P=0.70)$ & $R=-0.35(P=0.38)$ \\
$z$ & $R=-0.34(P=0.03)$ & $R=-0.27(P=0.48)$ \\
\hline
\end{tabular}

within subject correlation for the repeated measures during the $200 \mathrm{~m}$ event.

Previous studies have found a direct relationship between the IVVx and the $C$, indicating that the IVV could be a valid estimator of efficiency (Barbosa et al. 2005). However, this was found for a wide range of $v$; to the best of our knowledge, there is no study about IVV changes throughout a competitive event. During the $200 \mathrm{~m}$ front crawl event the $v$ and the stroke parameters associated (i.e. SF and SL) changed, which is in accordance with previous reports (Alberty et al. 2005; Craig et al. 1985). The $v$ of the first lap was higher than the other ones, meaning that a higher water resistance had to be overcome, since water resistance is related to $v^{2}$. As the $v$ is maintained for the rest of the event, changes in the SF and the SL occurs as a response to muscular fatigue (Figueiredo et al. 2010a; Caty et al. 2006; Stirn et al. 2011).

In the first lap, the association between the $C$ and the IVV $x$ was of $69 \%$, which evidences that swimmers who performed faster had a higher $C$ (di Prampero 1986), and lower propelling efficiency (Toussaint et al. 1988a) presenting lower/higher maximal/minimal $v$ peaks and also applying a better coordination (Seifert and Chollet 2009; Seifert et al. 2010b). The latter means less time spent between propulsive phases, and consequently lower IVV $x$. However, even when velocity effect was controlled a significant inverse relationship between the IVVx and the $C$ was found. At submaximal intensities, for the same velocity, the best swimmers are characterized as being more economic (i.e. presenting a lower C) (di Prampero 1986; Fernandes et al. 2006), having higher arm stroke efficiency (Seifert et al. 2010b; Toussaint 1990), higher SL (Craig et al. 1985; Seifert et al. 2010b) and higher lag time between propulsive actions (Seifert et al. 2010b), implying a higher IVVx. The presented relationship between the IVV $x$ and the $C$ suggests that swimmers: (1) were not fatigued, since they swam at a submaximal intensity for the first lap, as their goal is to achieve the best performance over the $200 \mathrm{~m}$; (2) may had adopted different coordinative strategies to reach the same goal, particularly at the SF values observed (Potdevin et al. 2006), and at early stages of the event, which result in $C$ variations (Seifert et al. 2010a).

In all the remaining laps, no association was found between the $C$ and the IVV ( $x, y$ and $z$ ), even when partial 
correlations were computed. This might be explained by the fact that in aquatic locomotion, total mechanical work is the sum of the work needed to overcome external forces (external work) and to accelerate and decelerate the limbs with respect to the centre of mass (internal work) (Barbosa et al. 2010b; Zamparo et al. 2005). External work is related to the position and velocity changes of the CM, the IVV being an estimation of it. Internal mechanical work is linked to the segmental kinematics, as the SL and the SF, which change during the course of the race (cf. Fig. 1). It was reported by Zamparo et al. (2005) that internal work has a cubic relationship with the $\mathrm{SF}\left(W_{\text {int }}=38.2 \mathrm{SF}^{3}\right)$; therefore, as it changes throughout the $200 \mathrm{~m}$ event, the total mechanical work also varies. Indeed, if the total mechanical work increases for the same overall efficiency, the $C$ rises as well (Overall efficiency $=W_{\text {tot }} x C^{-1}$ ). Since IVV do not take into account internal mechanical work, it might have a significant influence in the small $\mathrm{v}$ range when comparing to other incremental protocols (Barbosa et al. 2005; Fernandes et al. 2006).

The $C$ determinants (for a given $v$, technique, skill and gender) are the work to overcome hydrodynamic resistance $\left(W_{\mathrm{d}}\right)$ and the propelling efficiency; both expected to change with the appearance of fatigue. During a race it is expected that the propelling efficiency decrease and the $W_{\mathrm{d}}$ increases, and therefore the $C$ would also increase (Figueiredo et al. 2011b). In $200 \mathrm{~m}$ front crawl $v$ diminishes during the course of the event, propelling efficiency also decreases as observed before (Figueiredo et al. 2011b). However, the SF increased in the fourth lap, augmenting internal mechanical work (probably increasing the $C$ as well), as well as increasing continuity of the propulsive actions (probably diminishing the IVV) (Alberty et al. 2005; Figueiredo et al. 2010b). The $W_{\mathrm{d}}$ decreases also with the decrease of the $v$ (Toussaint et al. 1988b); nevertheless, the work that each swimmer must produce to overcome hydrodynamic resistance at a given $v$ is widely variable and dependent on individual morphology and technique (Vilas-Boas 1996; Chatard et al. 1990).

At the muscle level, classic experiments have shown that contraction type, length and speed, as well as fibre type and the recruitment pattern influence force generation and, therefore, metabolic cost, reflecting the effect of different contraction parameters (Sih and Stuhmiller 2003). In the $200 \mathrm{~m}$ particular effort, Caty et al. (2006) and Figueiredo et al. (2010a) found that muscular fatigue occur in the main muscles involved in swimming, which is expected also to influence the $C$ more than the IVV $x$.

Psycharakis et al. (2010) found greater magnitude in the IVVy and the IVV $z$ axes than in the IVV $x$, but their role and influence are not yet fully understood. In fact, in spite of their possible influence on the IVV $x$ and $v$, there is no relationship with the $C$ within each lap. This might be related to the fact that, when normalizing the SD used to calculate the coefficient of variation of the IVVy and the $\operatorname{IVV} z$ to the swimming direction $v$, the variations decreased to values ranging from 0.04 to 0.10 (unpublished data from our group), being much smaller than the IVV $x$ producing perhaps small effect in the $C$.

When analysing each subject throughout the $200 \mathrm{~m}$ event (within subject correlation) it was possible to observe a significant inverse relationship, of low to moderate effect, between the $C$ and the IVV $(x, y)$. These results showed the same relation as in the first lap, however, a small variance was explained (about 12\%) probably due to the influence of $v$ changes in the IVV. It is suggested that the $v$ changes and fatigue had a higher effect in the $C$ rather than in the IVV, since $C$ is variable (Figueiredo et al. 2011b) and the IVV is stable (Psycharakis et al. 2010) during this event. Also, several factors influence the $C$ more than the IVV during a competitive event, and so, the direct relationship between the IVV and the $C$ described in the literature for a large range of velocities, seem not to be applied during a competitive event, particularly the $200 \mathrm{~m}$ front crawl. This fact might dispel the idea of a useful relationship between the IVV and the $C$ as a performance predictor in competitive events. In addition, the between subjects correlation computed for the overall $200 \mathrm{~m}$ (mean values) did not suggest that the swimmers with higher $C$ values had higher IVV $(x, y$ and $z)$ values.

\section{Conclusion}

It is concluded that for each lap no relationship occurs between the IVV and the $C$, except for the first lap in the swimming direction, where rises in the IVV determine a lower $C$. The $200 \mathrm{~m}$ swimming event revealed a great specificity, in opposition to the relationship described in the literature between the IVV and the $C$, which suggests that the relation between these two parameters could not be used as a performance predictor in competitive events. In the future, other factors should be taken into account/ studied (e.g. changes in coordination, peripheral fatigue) in order to better understand the occurred changes.

Acknowledgments This investigation was supported by grants of Portuguese Science and Technology Foundation (SFRH/BD/38462/ 2007) (PTDC/DES/101224/2008-FCOMP-01-0124-FEDER-009577).

Conflict of interest The authors declare that they have no conflict of interest.

\section{References}

Abdel-Aziz Y, Karara H (1971) Direct linear transformation: from comparator coordinates into object coordinates in close range photogrammetry. In: Proceedings of the symposium on closerange photogrammetry. Church Falls, Illinois, pp 1-18 
Alberty M, Sidney M, Huot-Marchand F, Hespel JM, Pelayo P (2005) Intracyclic velocity variations and arm coordination during exhaustive exercise in front crawl stroke. Int J Sports Med 26(6):471-475. doi:10.1055/s-2004-821110

Alves F, Gomes-Pereira J, Pereira F (1996) Determinants of energy cost of front crawl and backstroke swimming and competitive performance. In: Troup JP, Hpllander AP, Strasse D, Trappe SW, Cappaert JM, Trappe TA (eds) Biomechanics and medicine in swimming VII. E \& FN Spon, London, pp 185-191

Baldari C, Bonavolonta V, Emerenziani GP, Gallotta MC, Silva AJ, Guidetti L (2009) Accuracy, reliability, linearity of Accutrend and Lactate Pro versus EBIO plus analyzer. Eur J Appl Physiol 107(1):105-111. doi:10.1007/s00421-009-1107-5

Barbosa TM, Keskinen KL, Fernandes R, Colaco P, Lima AB, VilasBoas JP (2005) Energy cost and intracyclic variation of the velocity of the centre of mass in butterfly stroke. Eur J Appl Physiol 93(5-6):519-523. doi:10.1007/s00421-004-1251-x

Barbosa TM, Fernandes R, Keskinen KL, Colaco P, Cardoso C, Silva J, Vilas-Boas JP (2006a) Evaluation of the energy expenditure in competitive swimming strokes. Int J Sports Med 27(11): 894-899. doi:10.1055/s-2006-923776

Barbosa TM, Lima F, Portela A, Novais D, Machado L, Colaço P, Gonçalves P, Fernandes R, Keskinen KL, Vilas-Boas JP (2006b) Relationships between energy cost, swimming velocity and speed fluctuation in competitive swimming strokes. Port J Sports Sci 6(S2):192-194

Barbosa T, Silva AJ, Reis AM, Costa M, Garrido N, Policarpo F, Reis VM (2010a) Kinematical changes in swimming front Crawl and Breaststroke with the AquaTrainer snorkel. Eur J Appl Physiol 109(6):1155-1162. doi:10.1007/s00421-010-1459-x

Barbosa TM, Bragada JA, Reis VM, Marinho DA, Carvalho C, Silva $\mathrm{AJ}$ (2010b) Energetics and biomechanics as determining factors of swimming performance: updating the state of the art. J Sci Med Sport 13(2):262-269. doi:10.1016/j.jsams.2009.01.003

Binzoni T, Ferretti G, Schenker K, Cerretelli P (1992) Phosphocreatine hydrolysis by 31P-NMR at the onset of constant-load exercise in humans. J Appl Physiol 73(4):1644-1649

Bland JM, Altman DG (1995a) Calculating correlation coefficients with repeated observations: Part $1-$ Correlation within subjects. BMJ 310(6977):446

Bland JM, Altman DG (1995b) Calculating correlation coefficients with repeated observations: Part 2-Correlation between subjects. BMJ 310(6980):633

Capelli C, Pendergast DR, Termin B (1998) Energetics of swimming at maximal speeds in humans. Eur J Appl Physiol Occup Physiol 78(5):385-393

Caty VY, Rouard AH, Hintzy F, Aujouannet YA, Molinari F, Knaflitz M (2006) Time-frequency parameters of wrist muscles EMG after an exhaustive freestyle test. Port J Sports Sci $6(\mathrm{~S} 2): 28-30$

Chatard JC, Lavoie JM, Lacour JR (1990) Analysis of determinants of swimming economy in front crawl. Eur J Appl Physiol Occup Physiol 61(1-2):88-92

Cohen J (1988) Statistical power analysis for the behavioral sciences, 2nd edn. Lawrence Erlbaum Associates, Hillsdale

Craig AB Jr, Pendergast DR (1979) Relationships of stroke rate, distance per stroke, and velocity in competitive swimming. Med Sci Sports 11(3):278-283

Craig AB Jr, Skehan PL, Pawelczyk JA, Boomer WL (1985) Velocity, stroke rate, and distance per stroke during elite swimming competition. Med Sci Sports Exerc 17(6):625-634

de Leva P (1996) Adjustments to Zatsiorsky-Seluyanov's segment inertia parameters. J Biomech 29(9):1223-1230

di Prampero PE (1986) The energy cost of human locomotion on land and in water. Int J Sports Med 7(2):55-72. doi:10.1055/ s-2008-1025736 di Prampero PE, Pendergast D, Wilson D, Rennie DW (1978) Blood lactic acid concentrations in high velocity swimming. In: Eriksson B, Furberg B (eds) Swimming medicine IV. University Park Press, Baltimore, pp 249-261

Fernandes RJ, Billat VL, Cruz AC, Colaco PJ, Cardoso CS, VilasBoas JP (2006) Does net energy cost of swimming affect time to exhaustion at the individual's maximal oxygen consumption velocity? J Sports Med Phys Fitness 46(3):373-380

Figueiredo P, Vilas Boas JP, Maia J, Goncalves P, Fernandes RJ (2009) Does the hip reflect the centre of mass swimming kinematics? Int J Sports Med 30(11):779-781. doi:10.1055/ s-0029-1234059

Figueiredo P, Sousa A, Gonçalves P, Pereira S, Soares S, Vilas-Boas JP, Fernandes RJ (2010a) Biophysical analysis of the $200 \mathrm{~m}$ front crawl swimming: a case study. In: Kjendlie P, Stallman R, Cabri J (eds) Proceedings of the XIth International Symposium for Biomechanics and Medicine in Swimming, Norwegian School of Sport Science, Oslo, pp 79-81

Figueiredo P, Vilas-Boas JP, Seifert L, Chollet D, Fernandes RJ (2010b) Inter-limb coordinative structure in a $200 \mathrm{~m}$ front crawl event. Open J Sports Sci 3:25-27

Figueiredo P, Machado L, Vilas-Boas JP, Fernandes RJ (2011a) Reconstruction error of calibration volume's coordinates for 3D swimming kinematics. J Hum Kinet 29:45-50

Figueiredo P, Zamparo P, Sousa A, Vilas-Boas JP, Fernandes RJ (2011b) An energy balance of the $200 \mathrm{~m}$ front crawl race. Eur J Appl Physiol 111(5):767-777. doi:10.1007/s00421-010-1696-Z

Gourgoulis V, Aggeloussis N, Kasimatis P, Vezos N, Boli A, Mavromatis G (2008) Reconstruction accuracy in underwater three-dimensional kinematic analysis. J Sci Med Sport 11(2):90-95. doi:10.1016/j.jsams.2007.02.010

Holmer I (1974) Physiology of swimming man. Acta Physiol Scand Suppl 407:1-55

Holmer I (1983) Energetics and mechanical work in swimming. In: Hollander AP, Huijing PA, Groot G (eds) Biomechanics and medicine in swimming. Human Kinetics Publishers, Champaign, pp 155-164

Keskinen KL, Rodriguez FA, Keskinen OP (2003) Respiratory snorkel and valve system for breath-by-breath gas analysis in swimming. Scand J Med Sci Sports 13(5):322-329

Kjendlie PL, Ingjer F, Stallman RK, Stray-Gundersen J (2004) Factors affecting swimming economy in children and adults. Eur J Appl Physiol 93(1-2):65-74. doi:10.1007/s00421-004-1164-8

Nigg B (1983) Selected methodology in biomechanics with respect to swimming. In: Hollander AP, Huijing PA, Groot G (eds) Biomechanics and medicine in swimming. Human Kinetics Publishers, Champaign, pp 72-80

Potdevin F, Bril B, Sidney M, Pelayo P (2006) Stroke frequency and arm coordination in front crawl swimming. Int $\mathrm{J}$ Sports Med 27(3):193-198. doi:10.1055/s-2005-837545

Prampero PE, Francescato MP, Cettolo V (2003) Energetics of muscular exercise at work onset: the steady-state approach. Pflugers Arch 445(6):741-746. doi:10.1007/s00424-002-0991-x

Psycharakis SG, Sanders RH (2009) Validity of the use of a fixed point for intracycle velocity calculations in swimming. J Sci Med Sport 12(2):262-265. doi:10.1016/j.jsams.2007.11.008

Psycharakis SG, Naemi R, Connaboy C, McCabe C, Sanders RH (2010) Three-dimensional analysis of intracycle velocity fluctuations in frontcrawl swimming. Scand $\mathbf{J}$ Med Sci Sports 20(1):128-135. doi:10.1111/j.1600-0838.2009.00891.x

Reis VM, Marinho DA, Barbosa FP, Reis AM, Guidetti L, Silva AJ (2010) Examining the accumulated oxygen deficit method in breaststroke swimming. Eur J Appl Physiol 109(6):1129-1135. doi:10.1007/s00421-010-1460-4

Ribeiro LF, Lima MC, Gobatto CA (2010) Changes in physiological and stroking parameters during interval swims at the slope of the 
d-t relationship. J Sci Med Sport 13(1):141-145. doi: 10.1016/j.jsams.2008.10.001

Seifert L, Chollet D (2009) Modelling spatial-temporal and coordinative parameters in swimming. J Sci Med Sport 12(4):495-499. doi:10.1016/j.jsams.2008.03.002

Seifert L, Komar J, Lepretre PM, Lemaitre F, Chavallard F, Alberty M, Houel N, Hausswirth C, Chollet D, Hellard P (2010a) Swim specialty affects energy cost and motor organization. Int J Sports Med 31(9):624-630. doi:10.1055/s-0030-1255066

Seifert L, Toussaint HM, Alberty M, Schnitzler C, Chollet D (2010b) Arm coordination, power, and swim efficiency in national and regional front crawl swimmers. Hum Mov Sci 29(3):426-439. doi:10.1016/j.humov.2009.11.003

Sih BL, Stuhmiller JH (2003) The metabolic cost of force generation. Med Sci Sports Exerc 35(4):623-629. doi:10.1249/01.MSS. 0000058435.67376.49

Stirn I, Jarm T, Kapus V, Strojnik V (2011) Evaluation of muscle fatigue during 100-m front crawl. Eur J Appl Physiol 111(1):101-113. doi:10.1007/s00421-010-1624-2

Toussaint HM (1990) Differences in propelling efficiency between competitive and triathlon swimmers. Med Sci Sports Exerc 22(3):409-415

Toussaint HM, Beek PJ (1992) Biomechanics of competitive front crawl swimming. Sports Med 13(1):8-24

Toussaint HM, Beelen A, Rodenburg A, Sargeant AJ, de Groot G, Hollander AP, van Ingen Schenau GJ (1988a) Propelling efficiency of front-crawl swimming. J Appl Physiol 65(6): 2506-2512

Toussaint HM, Hollander AP, de Groot G, van Ingen Schenau GJ, Vervoorn K, de Best H, Meulemans T, Schreurs W (1988b) Measurement of efficiency in swimming man. In: Ungerechts BE, Wilkie K, Reischle K (eds) Swimming science V. Human Kinetics Publishers, Champaign, pp 45-52

Vilas-Boas JP (1996) Speed fluctuations and energy cost of different breaststroke techniques. In: Troup JP, Hpllander AP, Strasse D, Trappe SW, Cappaert JM, Trappe TA (eds) Biomechanics and medicine in swimming VII. E \& FN Spon, London, pp 167-171

Vilas-Boas JP (2010) Biomechanics and medicine in swimming, past, present and future. In: Kjendlie KL, Stallman RK, Cabri J (eds) Biomechanics and medicine in swimming XI. Norwegian School of Sport Science, Oslo, pp 11-19

Vilas-Boas JP, Fernandes RJ, Barbosa TM (2010) Intra-cycle velocity variations, swimming economy, performance and training in swimming. In: Seifert L, Chollet D, Mujika I (eds) World book of swimming: from science to performance. Nova Science Publishers, Inc., USA, pp 120-140

Zamparo P, Pendergast DR, Mollendorf J, Termin A, Minetti AE (2005) An energy balance of front crawl. Eur J Appl Physiol 94(1-2):134-144. doi:10.1007/s00421-004-1281-4

Zamparo P, Capelli C, Pendergast D (2011) Energetics of swimming: a historical perspective. Eur J Appl Physiol 111(3):367-378. doi: 10.1007/s00421-010-1433-7 